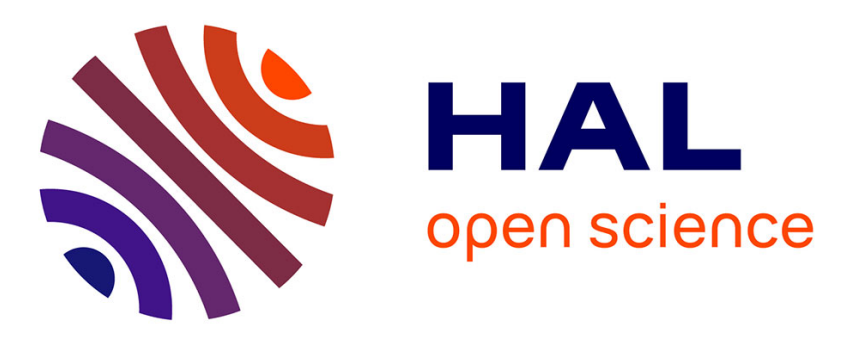

\title{
Mining induced seismicity : monitoring of a large scale salt cavern collapse
}

Emmanuelle Klein, Isabelle Contrucci, Ngoc-Tuyen Cao, Pascal Bigarre

\section{To cite this version:}

Emmanuelle Klein, Isabelle Contrucci, Ngoc-Tuyen Cao, Pascal Bigarre. Mining induced seismicity: monitoring of a large scale salt cavern collapse. 73. EAGE conference, May 2011, Vienne, Austria. pp.NC. ineris-00973616v2

\section{HAL Id: ineris-00973616 \\ https://hal-ineris.archives-ouvertes.fr/ineris-00973616v2}

Submitted on 11 Apr 2014

HAL is a multi-disciplinary open access archive for the deposit and dissemination of scientific research documents, whether they are published or not. The documents may come from teaching and research institutions in France or abroad, or from public or private research centers.
L'archive ouverte pluridisciplinaire HAL, est destinée au dépôt et à la diffusion de documents scientifiques de niveau recherche, publiés ou non, émanant des établissements d'enseignement et de recherche français ou étrangers, des laboratoires publics ou privés. 


\section{Mining Induced Seismicity - Monitoring of a Large Scale Salt Cavern Collapse}

E. Klein* (Ineris), I. Contrucci (Ineris), N.T. Cao (Ineris) \& P. Bigarre (Ineris)

To improve our understanding in large scale ground failure phenomenon induced by old underground mining works, a field experiment was undertaken in collaboration with the SOLVAY mining company: a solution mine was instrumented in 2004 previously to its collapse which was triggered in February 2009. as part of the mining scheme. This solution mine is located in the Lorraine salt basin (France). To monitor the cavern collapse, a multi-parameter system featuring high resolution microseismic linked to ground surface leveling (tacheometer and GPS-RTK) was used. The data transmitted for on-line processing offered daily insight of the evolution of the underground cavity.

The early signs of unstable evolution were detected during spring 2008: shifts in microseismic background regime end recurrent microseismic episodes were associated to a general upwards process of rock failure of the roof cavern, with no ground surface movement detected. The high microseismic regime of the cavern has convinced the operator to trigger the collapse by brine pumping. Three main microseismic regimes were then observed, each being well correlated with changes in both the surface subsidence rate and the brine level in the cavern. 


\section{Introduction}

Nowadays, risk management and mitigation related to underground extraction raises more than ever complex issues related to a constant increase in people's vulnerability induced by societal humandetermined paths of development. The instability of these underground works, especially when they are extended, may indeed result in the appearance of settlement, residual subsidence, localized or generalized collapse, potentially with significant social and economic impacts.

Thus, to improve our understanding in large scale ground failure phenomenon induced by underground mining works, a field experiment was undertaken by the partners of GISOS (a consortium of public organizations that includes INERIS and focusing research resources on underground geostructures) in collaboration with the SOLVAY company: a solution mine located in the Lorraine salt basin (at Cerville-Buissoncourt southwards from Nancy, France) was instrumented in 2004 previously to its collapse which was triggered in February 2009, as part of the mining scheme. To monitor the cavern collapse a permanent multi-parameter monitoring system featuring high resolution microseismic along with surface leveling monitoring was set up.

In this extended abstract, we first describe the on-site instrumentation installed by INERIS and present the data collected during this experimentation. We will then see that this unique dataset enables to accurately identify the main stages in the evolution of the solution mine up and help to demonstrate the full capability of multi-parameter monitoring and on-line expertise to enhance the risk management strategy in this domain.

\section{Site description and instrumentation layout}

The geology of the site is characterized by a succession of sub-horizontal layers from the ground surface down to the salt deposit which lies between 180 and $260 \mathrm{~m}$ depth. The overburden consists in (1) alternating layers of clay-sandstone-marl up to a depth of $\sim 123 \mathrm{~m}$; (2) a massive, stiff and slightly fractured competent bed of dolomite and anhydrites (known as Beaumont dolomite layer), $\sim 8.5 \mathrm{~m}$ thick; (3) $\sim 60 \mathrm{~m}$ of marls with more or less indurated anhydrites; (4) the salt layer underlying to a depth of $\sim 280$ meters.

The salt mining method set-up by SOLVAY consists in producing brine by intensive dissolution using the "channel and drilling method" (Figure 1-a-b). This technique relies on the injection of fresh water (or recycle brine) through dedicated wells placed upstream of two parallel lines of solution mining wells that reach the bottom of the salt deposit. Brine is extracted downstream. This technique leads to the formation of a cavern in line with the water injection drilling holes. It develops during operation until the cavern roof collapses (Figure 1-b). This ultimately results in the formation of a sinkhole that reaches the surface.

The permanent monitoring system installed by INERIS based on a SYTGEM multi-parameter system is detailed in Contrucci et al. (2010a). It comprised (Figure 1-c):

- A high resolution microseismic network made up of nine sensors including four 3D sensors, all equipped with miniature wideband geophones $(40-1000 \mathrm{~Hz})$ distributed on site and cemented into boreholes at depths of between 2 and 125 meters.

- A surface leveling monitoring system comprising a motorised laser tacheometer measuring the position of 17 targets, aligned both inside and outside the subsidence area and two RTK (Real Time Kinematic) differential GPS stations (one placed on a stable zone, the second positioned at the very centre of the expected collapsing area).

The automatic on-line microseismic data processing was performed by the SYTMIS software from INERIS. It was parameterized on a routine basis included P-wave picking using an STA/LTA algorithm and 3D location of events based on a non-linear inversion method (Contrucci et al. 2010b). In practice it was difficult to achieve reliable automatic on-line S-wave picking and thus improved 3D location, because far-field assumptions were not always valid during the experiment. In addition, 
some seismograms did not show any S arrivals: in such cases it was therefore difficult to define a criterion for no S-waves picking. For these reasons we chose not to use these $\mathrm{S}$ phases for automatic location. The velocity model used that comprised 3 layers, according to the geology (see Contrucci et al. 2010a for full details) was defined through statistic inversion of calibration data (shots carried out on surface in 2005).

The accuracy of $+/-5 \mathrm{~mm}$ for the GPS-RTK measurements was obtained thanks to the short interreceiver distance and the high stacking. The data collected by the tacheometer, although strongly sensitive to meteorological variations, showed a similar precision for the closest targets when applying a simple moving average to a few measurement cycles.

a)

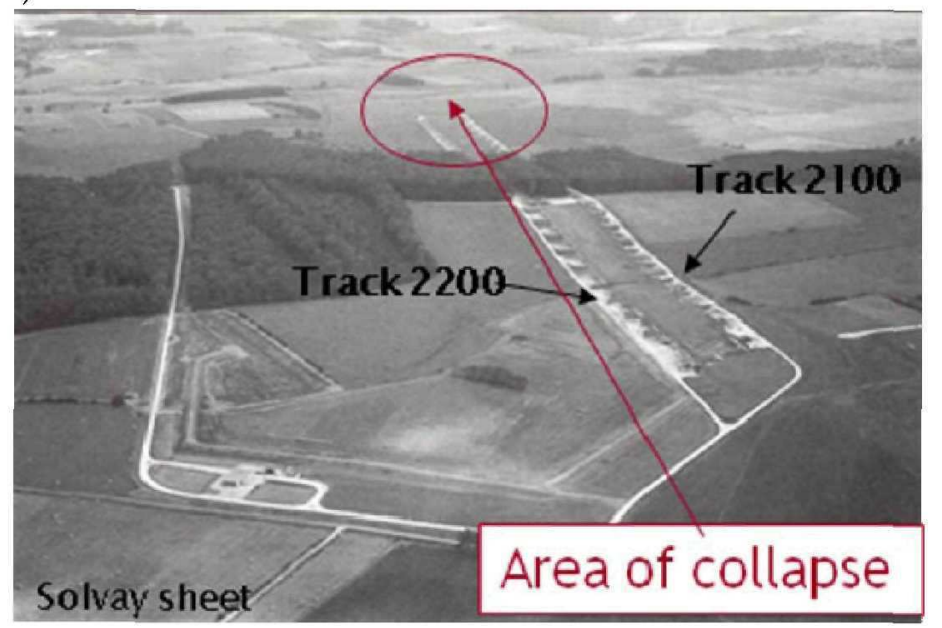

b)

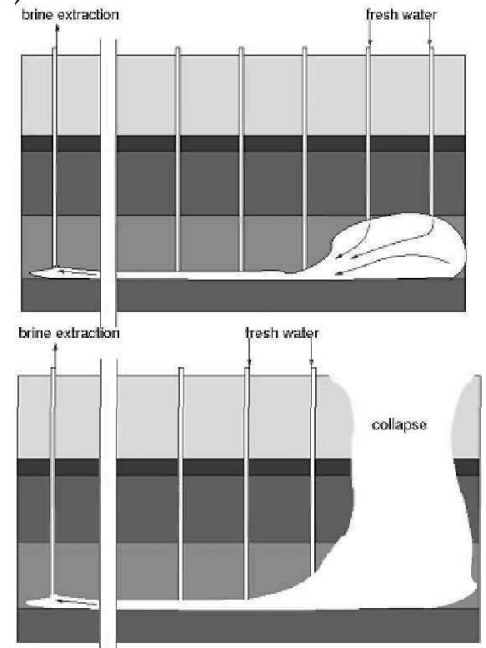

c)

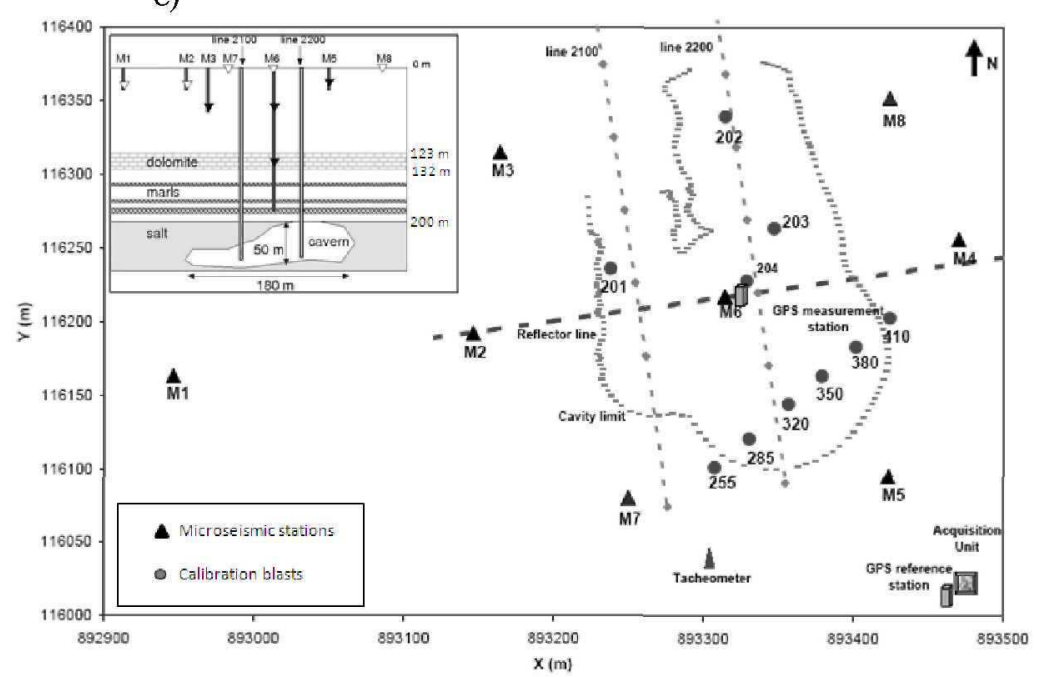

Figure 1: a) View of the site before the collapse. b) Illustration of the "channel and drilling method". c) Location of the multi-parameter monitoring network and simplified $E$-W geological section showing the position of the $3 D$ microseismic probes (black symbols) and $1 D$ (unfilled symbols) with depth.

\section{Brief overview of the dataset}

Very few microseismic events were recorded until February 2008, except during two small microseismic surges in May 2007. From March 2008, the microseismic trend was marked by several episodes of important activity (more than 10,000 events recorded in few days) and a change in the background noise that reached around 25 events per day (Klein et al., 2008). Besides, the spatial and time migrations of the microseismogenic zone indicated clearly a rather vertical development of the cavern dome along with an apparent lateral dissymmetry. These observations were confirmed by 
gamma ray well-logging showing that massive marls roof falls of $\sim 500,000 \mathrm{~m} 3$ occurred between February and May 2008 with a transverse asymmetric roof elevation (Klein et al., 2008). From that point, decision was taken to definitely close the surface access to the zone, even though no significant subsidence was observed. At that time, the upper part of the geological overburden was indeed showing a rather stiff elastic response. However, it was admitted that the cavern had reached its critical dimensions based on numerical modeling considerations and expertise (Contrucci et al. 2010a). To accelerate the collapse triggering, SOLVAY decided to progressively lower the brine level. Intensive brine extraction began on the 10th February 2009 at 7:00 am (local time) and continued until the general collapse, three days later, on the 13th February 2009 at 5:45 am (local time). Figure 2 shows the microseismic activity recorded during that period versus: (a) brine level and (b) subsidence. This figure also illustrates the extraction regime which was conducted into two main phases: 1- a first pumping stage with a decrease in the brine level by 50 meters; 2- quasi-continuous pumping up to the collapse between 400 and $600 \mathrm{~m} 3 / \mathrm{h}$ up to the collapse.

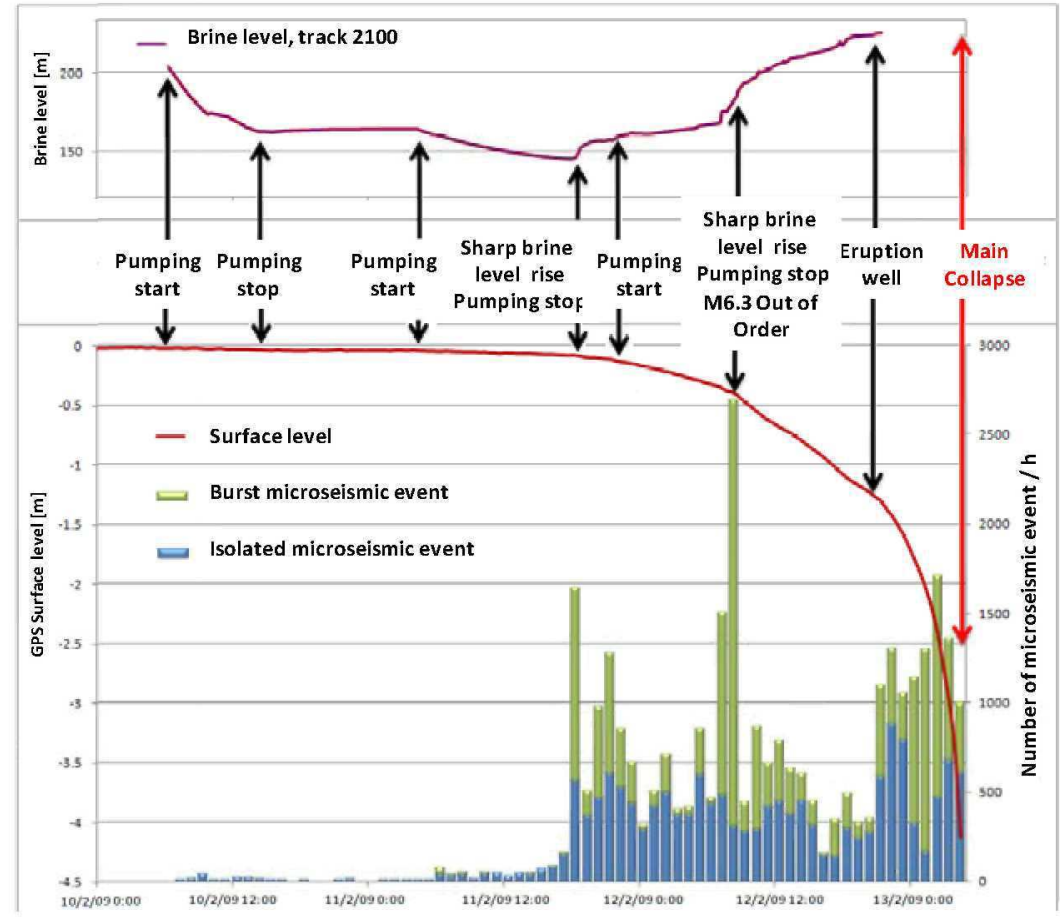

Figure 2: Between the 10th and 13th February 2009: Top) brine level measured at the extraction well (1 km away from the cavern). Down) Number of microseismic events recorded per hour superimposed to surface subsidence measured by the GPS-RTK device.

During the first day of pumping, neither significant microseismicity nor surface subsidence could be observed. The impact of the diminution of the brine level became really effective at the end of the second day (Contrucci et al. 2010) with a sudden acceleration of the microseismic energy release rate, showing more than 1500 events in one hour (Figure 2). This microseismic swarm coincided with a dynamic rise of 9 meters of the brine level and marked a change of the subsidence regime (Figure 2), which velocity reached then $\sim 0.02 \mathrm{~m} / \mathrm{h}$. Beyond that stage, the sustained microseismic activity increased rapidly faster than during any other period. From that point, the pumping regime was not powerful enough to compensate the brine level rise, at the extraction wells, due to the pressure applied on the system by the overburden. The major peak of activity occurred early the third day, when the cumulative subsidence reached $\sim 0.40$ meters. It coincided first with loud acoustic noises heard on site and, later on, with the breakdown of the microseismic probe installed in the Beaumont dolomite bed at 125 meters depth. These observations along with on-line 3D location results show that this major peak of activity is related to the global failure of the Beaumont dolomite rock bed (Figure $3-\mathrm{a}$ ). This major peak was then followed by an acceleration phase of the subsidence rate, which ultimately reached 1 meter per hour (Contrucci et al. 2010a). Less than 24 hours later, the ground surface 
collapsed leading to a crater of $\sim 150$ meters in diameter (Figure 3-b). More than 30,000 events were recorded during the last 4 days preceding the collapse. The last GPS measurements, during the ground collapse and flooding of the zone, indicated a cumulative subsidence of 4 meters in the center of the area (Figure 2). Figure 3-b shows a photo of the crater few days after the cavern collapse.

\section{Conclusion}

Although in-depth data processing is still going on, the complete dataset seems to highlight a probable global dual mechanism. First: deep, slow and barely detectable rock mass fracturing starting from the salt roof up to the Beaumont dolomite bed. This lasts around one year and can almost only be monitored by a high resolution microseismic system. Second: a brutal and sudden failure of the overburden up to the surface, over less than one day, well detected by the ground surface displacement system. This second and sudden stage occurs rapidly after the brittle failure of the Beaumont dolomite bed. If the complex and delayed behavior of this bed between these two stages is not obvious, it can undoubtedly be monitored by high resolution microseismic system.

a)

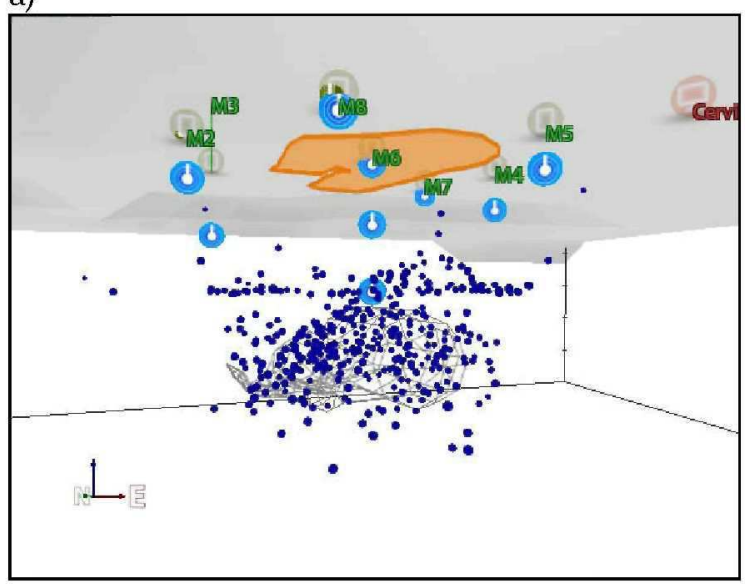

b)

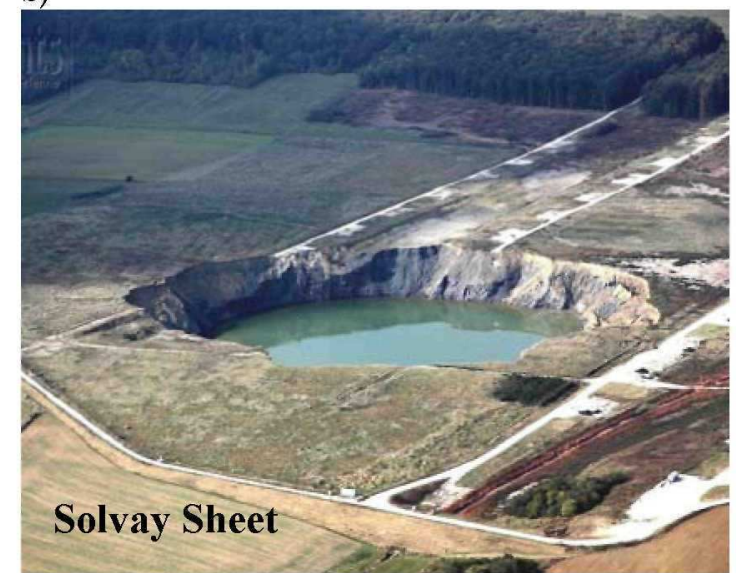

Figure 3: a) 3D view of the microseismic events between the first and the second surge of activity. $b$ ) Photo of the crater observed on site few days after the cavern collapse.

This experiment highlights the potential of microseismic monitoring as a useful tool to assess overburden damage and salt cavern evolution. Thus, to ensure in time actions for risk management strategy in such geological context, an early warning system should clearly focus on microseismicity prior to the Beaumont dolomite failure. Besides, this unique four year experiment also demonstrates the full capability of multi-parameter monitoring and on-line expertise to enhance the risk management strategy in this domain.

\section{References}

Contrucci I., Klein E., Cao N.T., Daupley X., P. Bigarré, Multi-parameter monitoring of a solution mining cavern collapse: first insight of precursors, C. R. Geosciences (2010a), doi: 10.1016/j.crte.2010.10.007.

Contrucci, I., Klein, E., Bigarré, P., Lizeur, A., Lomax, A., and Bennani, M., 2010b. Management of post-mining large-scale ground failures: blast swarms field experiment for calibration of permanent microseismic early-warning systems, Pure Appl. Geophys., doi: 10.1007/s00024-009-0005-4.

Klein E., Contrucci I., Daupley X., Hernandez O., Bigarré P., Nadim C., Cauvin L., Pierson M., Experimental monitoring of a solution-mining Cavern in Salt: identifying and analyzing earlywarning signals prior to collapse, SMRI Fall 2008 Technical Conference, 12-15 October 2008, Galveston (Austin), Texas, USA, (2008) 135-146. 